\title{
NOTE ON ANONYMITY \\ AND LANGUAGE
}

Most of the individuals and health facilities mentioned in this book have been given pseudonyms. Exceptions include individuals, health facilities, and organizations identified by name in public documents such as newspapers, reports, books, or articles. Throughout the book, I use my interlocutors' words in French (and in a few instances, Wolof). For example, research participants used the French term l'interrogation to describe the practice of questioning post-abortion care patients. While the equivalent in English would be "the medical interview," during which the health worker gathers information from the patient for the purposes of diagnosis and therapy, in the Senegalese context the possibility of illegal induced abortion injected an investigative quality into this practice. I discuss l'interrogation in greater detail in chapter 3. In American English, the term "abortion" almost always refers to induced abortion or voluntary pregnancy termination. In French, the term avortement may refer to either spontaneous abortion (miscarriage) or induced abortion. When discussing post-abortion care, my interlocutors did not always distinguish between spontaneous abortion (avortement spontané or fausse couche) and induced abortion (avortement provoqué). 

DYING TO COUNT 


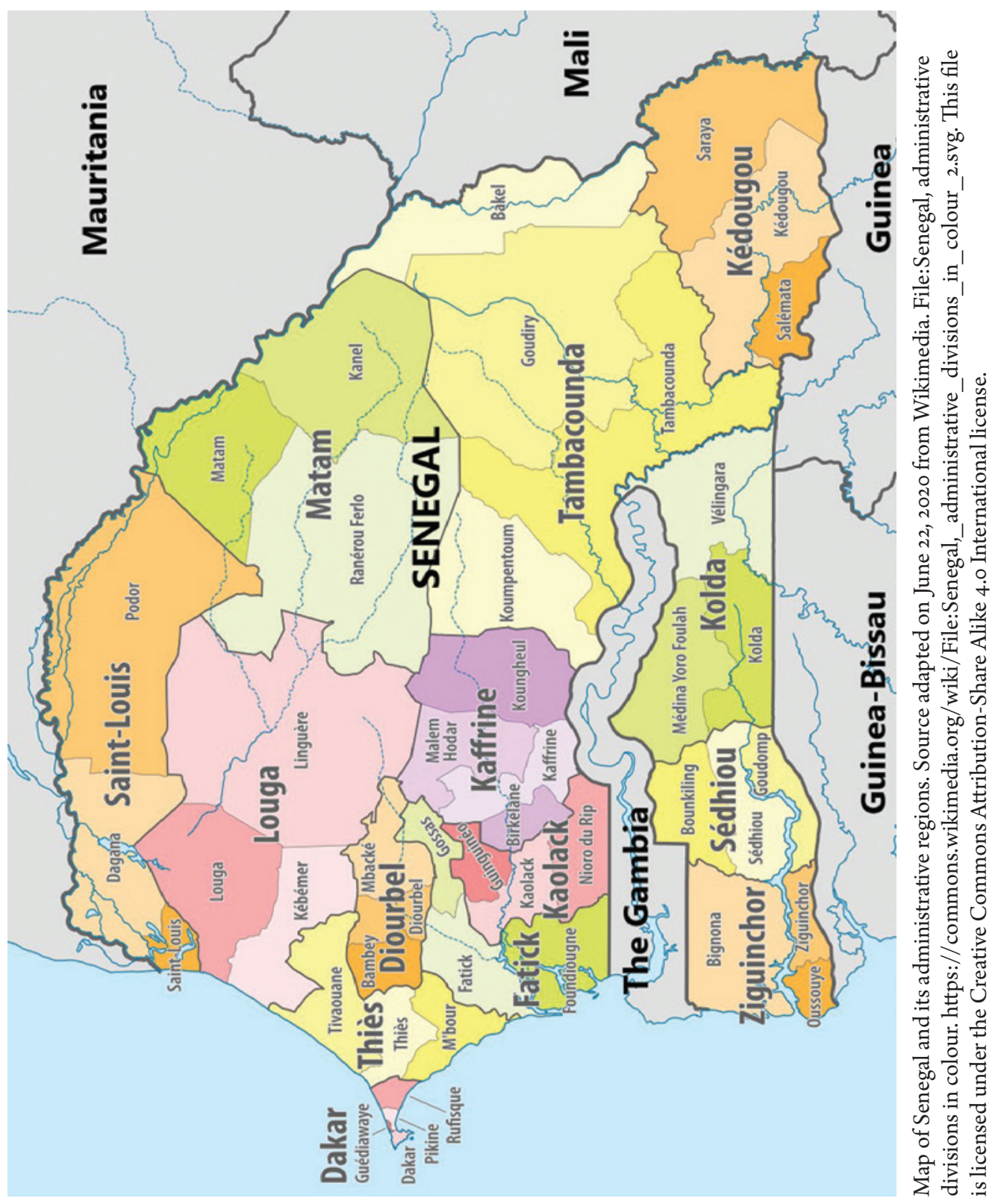

